Original Article

\title{
STABILITY INDICATING RP-HPLC METHOD FOR SIMULTANEOUS ESTIMATION OF DOSULEPIN HYDROCHLORIDE AND METHYLCOBALAMIN IN TABLET DOSAGE FORM
}

\author{
RADHIKA SHAH $^{1 *}$, RAGIN SHAH ${ }^{2}$ \\ ${ }^{1}$ School of Pharmacy, R. K. University, Bhavnagar Highway, Kasturbadham, Rajkot 360020, Gujarat, India, ${ }^{2}$ Arihant School of Pharmacy \\ and Bioresearch Institute, Adalaj, Gandhinagar, Gujarat, India \\ Email: radhika.shah75@gmail.com
}

Received: 17 Apr 2017, Revised and Accepted: 14 Jun 2017

ABSTRACT

Objective: To develop an accurate, simple, rapid, precise, economic and stability indicating RP-HPLC method for the simultaneous estimation of dosulepin hydrochloride and methylcobalamin in tablet dosage form and validate as per ICH guidelines.

Methods: The column used was Kromasil $\mathrm{C}_{18}(250$ X $4.6 \mathrm{~mm}, 5 \mu \mathrm{m})$, with a mobile phase containing acetonitrile: phosphate buffer pH 3 adjusted with o-phosphoric acid (60:40) with a flow rate of $1 \mathrm{ml} / \mathrm{min}$. The effluents obtained were monitored at $285 \mathrm{~nm}$ with photodiode array detector. Dosulepin hydrochloride and methylcobalamin were subjected to stress degradation conditions like hydrolysis (acid and base), oxidation, thermal and photolysis degradation. The samples subjected to stress degradation were analysed by the developed method.

Results: The retention time for dosulepin hydrochloride and methylcobalamin was found to be $7.99 \mathrm{~min}$ and 1.97 min, respectively. The linearity of developed method was achieved in the range of $165-495 \mu \mathrm{g} / \mathrm{ml}$ for dosulepin hydrochloride and $5-15 \mu \mathrm{g} / \mathrm{ml}$ for methylcobalamin. The detection (LOD) and quantitation (LOQ) limits were found to be $0.75 \mu \mathrm{g} / \mathrm{ml}$ and $2.28 \mu \mathrm{g} / \mathrm{ml}$ for dosulepin hydrochloride and $0.040 \mu \mathrm{g} / \mathrm{ml}$ and $0.121 \mu \mathrm{g} / \mathrm{ml}$ for methylcobalamin respectively. In the stability studies, it was observed that there is no interference of the degradation products with drug samples.

Conclusion: An accurate simple, rapid, precise, linear and stability indicating RP-HPLC method was developed for simultaneous quantitative estimation of dosulepin hydrochloride and methylcobalamin both in bulk and pharmaceutical formulation. The method was validated as per ICH guidelines. This method holds good for the routine analysis of dosulepin hydrochloride and methylcobalamin in various pharmaceutical industries as well as in academics.

Keywords: Stability, RP-HPLC, Validation, Dosulepin hydrochloride, Methylcobalamin

(c) 2017 The Authors. Published by Innovare Academic Sciences Pvt Ltd. This is an open access article under the CC BY license (http://creativecommons.org/licenses/by/4.0/) DOI: http://dx.doi.org/10.22159/ijap.2017v9i4.19204

\section{INTRODUCTION}

Dosulepin hydrochloride (fig. 1) chemically is 1-Propanamine, 3dibenzo [b, e] thiepin-11(6H)-ylidene- N,N-dimethyl-, hydrochloride. Dosulepin belongs to the category of drugs referred to as tricyclic antidepressants and having anxiolytic properties. Dosulepin works by preventing serotonin and noradrenaline from being reabsorbed back into the nerve cells in the brain. This helps prolong the mood lightening effect of any released noradrenaline and serotonin. In this way, dosulepin helps relieve depression [1].

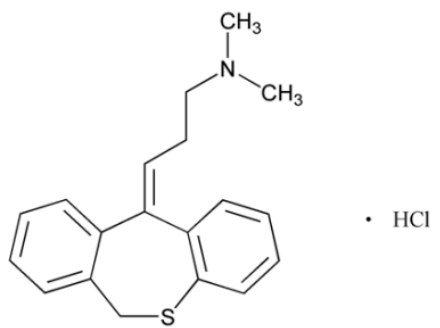

Fig. 1: Chemical structure of dosulepin hydrochloride [2]

Methylcobalamin chemically is alpha-(5,6-dimethylbenzimidazolyl) methylcobalamin (fig. 2). It is a form of vitamin $\mathrm{B}_{12}$ (cyanocobalamin) and differs from that the cyanide is replaced by a methyl group. Vitamin $B_{12}$ is an essential material for the growth, cell reproduction, hematopoiesis and synthesis of genetic material like nucleoprotein and myelin. Cobalamin is generally used in the treatment of peripheral neuropathy, diabetic neuropathy and as a preliminary treatment for amyotrophic lateral sclerosis. Cobalamin is necessary for DNA synthesis, the formation of red blood cells and maintenance of the nervous system, growth and development of children [3-5].

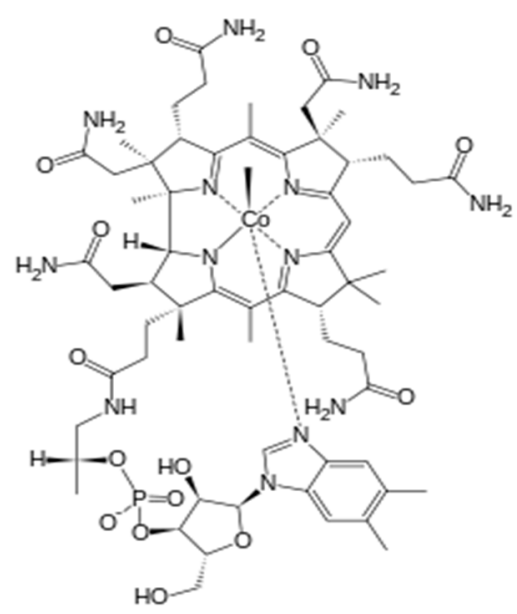

Fig. 2: Chemical structure of methylcobalamin [6]

Combination therapy of dosulepin hydrochloride and methylcobalamin is used for the treatment of neuropathic pain.

In literature, various spectrophotometric methods and RP-HPLC methods have been reported for quantitation of dosulepin hydrochloride and methylcobalamin in individual and combined available market formulation [1, 7-16]. But only one assay has been reported for the stability of the same [17]. The present study focuses on developing a new stability assay method for dosulepin hydrochloride and methylcobalamin in combination. This method will provide new insight into the stability studies of this combination. Moreover, this novel validated method (as per ICH guidelines [18-19]) has applicability in industry as well as academia. 


\section{MATERIALS AND METHODS}

Pharmaceutical grade dosulepin hydrochloride was procured from Elite Pharmaceutical Private Limited, Ahmedabad and methylcobalamin was obtained from Aum Laboratories, Ahmedabad. The marketed formulation Prothiaden M containing dosulepin hydrochloride $50 \mathrm{mg}$ and methylcobalamin $1500 \mathrm{mcg}$ was purchased from the local market. Methanol, orthophosphoric acid, acetonitrile and HPLC grade water were obtained from Merck. All solvents used were HPLC grade. RP-HPLC Shimadzu (LC 20ATVP) model with Spin chrome (LC Solutions) software was employed in this method. Analytical column used for the separation of analytes was Kromasil $\mathrm{C}_{18}(250$ X $4.6 \mathrm{~mm}, 5 \mu \mathrm{m})$.

\section{Methods}

\section{Selection of wavelength}

Standard solutions of dosulepin hydrochloride and methylcobalamin were prepared at the concentration of $10 \mu \mathrm{g} / \mathrm{ml}$ and scanned using
UV-Visible spectrophotometer at the range of 200-400 nm. The isosbestic point selected for simultaneous estimation was $285 \mathrm{~nm}$ based on combined UV spectrums of dosulepin hydrochloride and methylcobalamin (fig. 3).

\section{Chromatographic conditions}

The developed method used a reverse phase, Kromasil $\mathrm{C}_{18}$ column $(250 \times 4.6 \mathrm{~mm}, 5 \mu \mathrm{m})$. The mobile phase used was acetonitrile: phosphate buffer pH 3 adjusted with o-phosphoric acid (60:40) at a flow rate of $1.0 \mathrm{ml} / \mathrm{min}$ and a detection wavelength of $285 \mathrm{~nm}$ using a photodiode array detector.

\section{Preparation of phosphate buffer}

Accurately weighed $2.7 \mathrm{~g}$ of potassium dihydrogen phosphate $\left(\mathrm{KH}_{2} \mathrm{PO}_{4}\right)$ and $6 \mathrm{ml}$ of triethylamine were dissolved in $800 \mathrm{ml}$ of water; the $\mathrm{pH}$ was adjusted to 3.0 with o-phosphoric acid and final volume adjusted to $1000 \mathrm{ml}$ with water. The buffer was filtered to remove all fine undissolved particles.

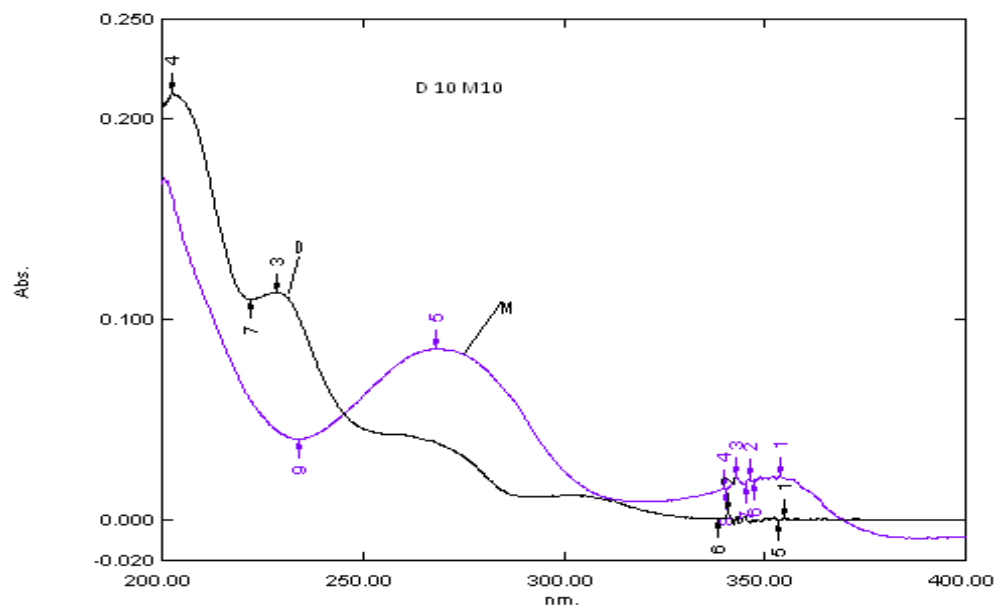

Fig. 3: UV overlap spectrum of dosulepin hydrochloride and methylcobalamin

\section{Preparation of mobile phase}

A mixture of 60 volumes of acetonitrile and 40 volumes of phosphate buffer was prepared. The mobile phase was sonicated for 10 min to remove gases.

\section{Preparation of standard solutions}

A standard stock solution of dosulepin hydrochloride was prepared by dissolving $330 \mathrm{mg}$ of dosulepin hydrochloride in $10 \mathrm{ml}$ of mobile phase. After that, the solution was filtered and sonicated for $5 \mathrm{~min}$ and volume adjusted to $100 \mathrm{ml}$ with mobile phase giving a final concentration of $3300 \mu \mathrm{g} / \mathrm{ml}$. Similarly, a standard stock solution of methylcobalamin was prepared by dissolving $10 \mathrm{mg}$ of methylcobalamin in $10 \mathrm{ml}$ of mobile phase and the solution was filtered, sonicated for $5 \mathrm{~min}$. The final concentration of $100 \mu \mathrm{g} / \mathrm{ml}$ was achieved by adjusting the volume to $100 \mathrm{ml}$

\section{Sample preparation}

Twenty tablets were weighed and finely powdered. The powder equivalent to $330 \mathrm{mg}$ dosulepin hydrochloride and $10 \mathrm{mg}$ methylcobalamin was accurately weighed. This powder was transferred to the volumetric flask of $100 \mathrm{ml}$ capacity and dissolved in $50 \mathrm{ml}$ of mobile phase. The flask was sonicated for $10 \mathrm{~min}$. The flask was shaken and volume was made up to the mark with the mobile phase. The above solution was filtered through Whatman filter paper $(0.45 \mu)$. This solution is expected to contain $3300 \mu \mathrm{g} / \mathrm{ml}$ of dosulepin hydrochloride and $100 \mu \mathrm{g} / \mathrm{ml}$ methylcobalamin. The same solution was used for the estimation of dosulepin hydrochloride and methylcobalamin.

\section{Stress degradation studies}

Forced degradation studies were performed to know the degradation products and to establish degradation pathway for dosulepin hydrochloride and methylcobalamin. The study involves acid hydrolysis wherein sample solution was treated with $0.1 \mathrm{M} \mathrm{HCl}$ at room temperature for $24 \mathrm{~h}$. The sample solution was treated with $0.1 \mathrm{M} \mathrm{NaOH}$ at room temperature for $24 \mathrm{~h}$ to study alkali hydrolysis. Oxidative degradation studies involved $3 \% \mathrm{H}_{2} \mathrm{O}_{2}$ treatment of sample solution at room temperature for $24 \mathrm{~h}$. The samples were placed in hot air oven at $105^{\circ} \mathrm{C}$ for $6 \mathrm{~h}$ to study thermal degradation. For photolytic stress studies, samples were exposed to sunlight for $7 \mathrm{~d}$ [19].

\section{RESULTS AND DISCUSSION}

\section{Method development}

Different chromatographic conditions were tried for better separation and resolution. Kromasil $\mathrm{C}_{18}(250 \times 4.6 \mathrm{~mm}, 5 \mu \mathrm{m})$ column was found satisfactory. Peak purity of dosulepin hydrochloride and methylcobalamin was checked using photodiode array detector and wavelength of $285 \mathrm{~nm}$ was considered satisfactory for detecting both the drugs with adequate sensitivity. A variety of solvents in different ratios over a wide range of $\mathrm{pH}$ were tried, but either peak shape was broad or resolution was not good. Repeated trials were performed in order to obtain good, sharp peak with an efficient resolution between two peaks of dosulepin hydrochloride and methylcobalamin. This was achieved by performing isocratic HPLC on a $\mathrm{C}_{18}$ column. The run time was $12 \mathrm{~min}$ in an isocratic trial with the use of mobile phase consisting of acetonitrile: phosphate buffer pH 3.0 (60:40) on a Kromasil $\mathrm{C}_{18}$ $(250 \times 4.6 \mathrm{~mm}, 5 \mu \mathrm{m})$ column with flow rate $1.0 \mathrm{ml} / \mathrm{min}$ and detection wavelength $285 \mathrm{~nm}$. This developed method gave satisfactory results in terms of retention time, resolution, symmetry and sensitivity. A typical RP-HPLC chromatogram for simultaneous determination of dosulepin hydrochloride and methylcobalamin from the standard can be seen in fig. 4 . 


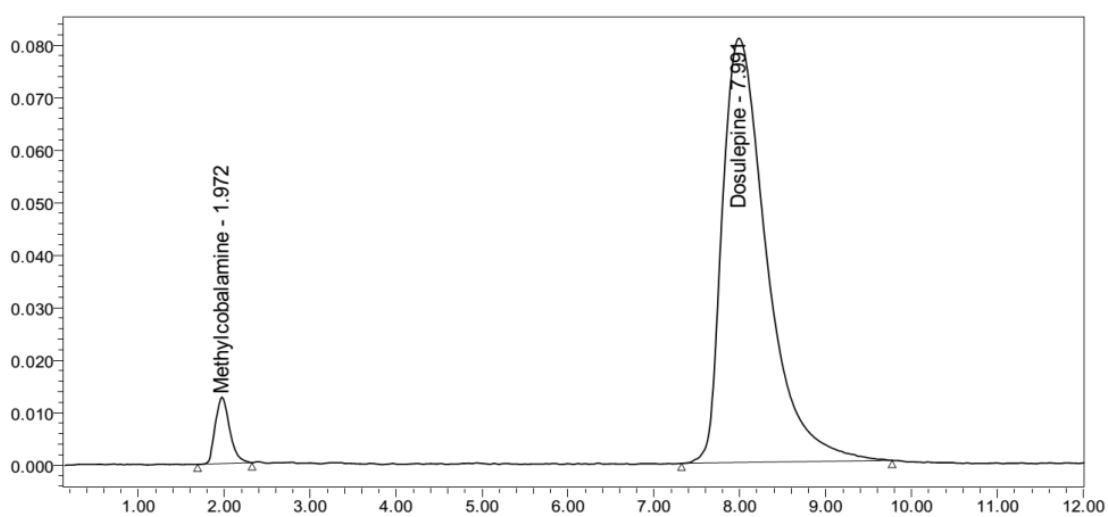

Fig. 4: Typical chromatogram of standard solution

\section{Method validation}

The developed RP-HPLC method was validated for parameters like system suitability, linearity, accuracy, precision, limit of detection (LOD), limit of quantitation (LOQ) and robustness according to ICH guidelines [18-19].

\section{System suitability}

Standard solutions were prepared as per the test method and injected into the chromatographic system. The system suitability parameters like theoretical plates, resolution and tailing factor were evaluated. The system suitability parameters were tabulated in table 1. All the parameters were found to be within the limits [20-21].

\section{Linearity}

The linearity of the method was determined by assaying dosulepin hydrochloride and methylcobalamin standard stock solution at five different concentrations. Concentrations of dosulepin hydrochloride taken were $165,247.5,330,412.5$ and $495 \mu \mathrm{g} / \mathrm{ml}$ and for methylcobalamin $5,7.5,10,12.5$ and $15 \mu \mathrm{g} / \mathrm{ml}$. The calibration curves were plotted between the responses of peak area versus concentration of the analyte. Least-squares linear regression analysis was performed for the calibration curves (fig. 5 and 6). The results have shown an excellent correlation between peak areas and concentration within the concentration range of $165-495 \mu \mathrm{g} / \mathrm{ml}$ for dosulepin hydrochloride, $5-15 \mu \mathrm{g} / \mathrm{ml}$ for methylcobalamin (table 2). The correlation coefficients were found to be 0.999 for dosulepin hydrochloride and 0.994 for methylcobalamin, which meet the method validation acceptance criteria [20-21] and hence the method was said to be linear for both the drugs.

\section{Precision}

The precision of the method was verified by two various methodsrepeatability and reproducibility (intraday and interday precision)

Table 1: Results of system suitability studies

\begin{tabular}{llll}
\hline Parameters & Acceptance limits & Dosulepin hydrochloride & Methylcobalamin \\
\hline Retention time & - & 7.991 & 1.972 \\
Theoretical plates & NLT 2000 & 2770 & 2344 \\
Tailing factor (T) & NMT 2 & 1.736 & 1.298 \\
Resolution & NLT 2 & 9.55 & 9.55 \\
\hline
\end{tabular}

\#NLT: Not less than. \# NMT: Not more than

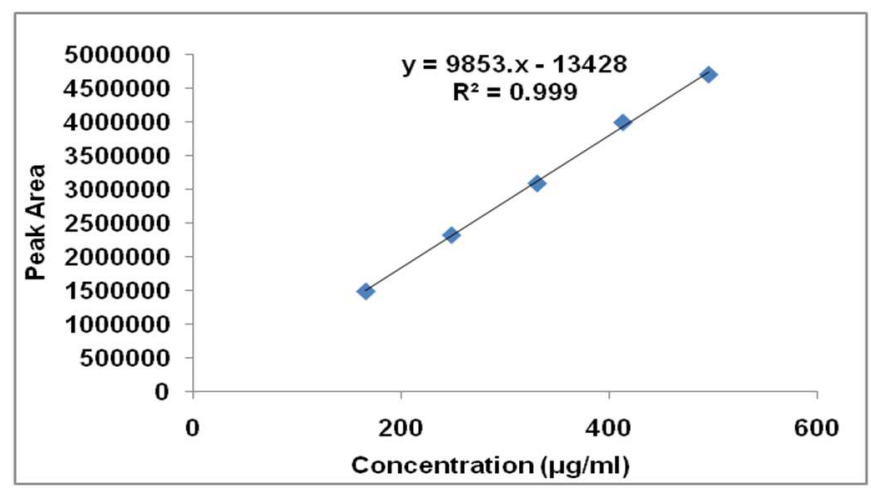

Fig. 5: Linearity chart for dosulepin hydrochloride

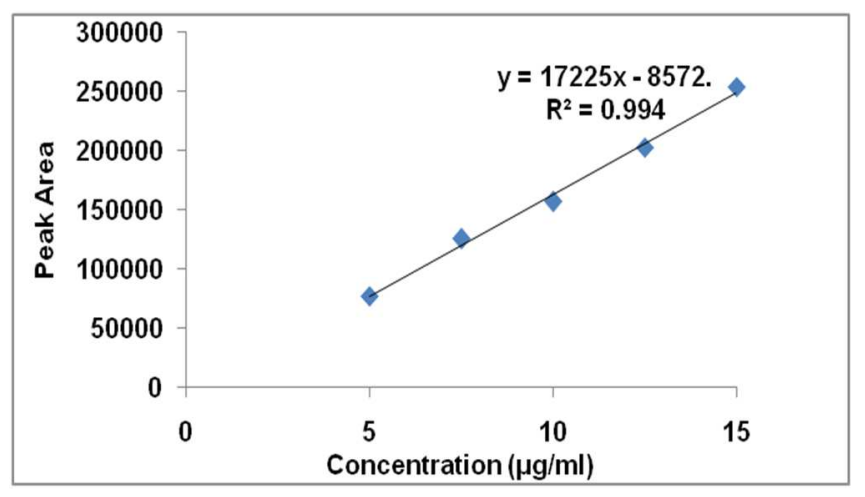

Fig. 6: Linearity chart for methylcobalamin

Table 2: Linearity data for dosulepin hydrochloride and methylcobalamin

\begin{tabular}{lll}
\hline Parameters & Dosulepin hydrochloride & Methylcobalamin \\
\hline Linearity range $(\mu \mathrm{g} / \mathrm{ml})$ & $165-495$ & $5-15$ \\
Regression equation & $\mathrm{y}=9853 . \mathrm{x}-13428$ & $\mathrm{y}=17225 \mathrm{x}-8572$ \\
Correlation coefficient & 0.999 & 0.994 \\
Average \%RSD (Peak area, $\mathrm{n}=5)$ (Linearity) & 0.16 & 0.39 \\
\hline
\end{tabular}

\# n: Number of injections for liniarity= 5, \# \%RSD: Relative standard deviation 


\section{Repeatability}

The sample solution was prepared at working concentration of 330 $\mu \mathrm{g} / \mathrm{ml}$ for dosulepin hydrochloride and $10 \mu \mathrm{g} / \mathrm{ml}$ for methylcobalamin as described earlier. Repeatability analysis was carried out by injecting the sample 6 times for the same concentration of both the drugs. The results of repeatability study are provided in table 3 .

The method was found to be precise as the $\%$ RSD values calculated were within the limits for repeatability [20-21].

\section{Reproducibility (intraday and interday precision)}

Intraday and interday precision were carried out using three replicates of different concentrations $(165,330$ and $495 \mu \mathrm{g} / \mathrm{ml}$ for dosulepin hydrochloride; $5, \quad 10$ and $15 \mu \mathrm{g} / \mathrm{ml}$ for methylcobalamin). The results of intraday and interday precision are tabulated in table 4

The method was found to be precise as the \% RSD values calculated were within the limits for reproducibility [20-21].

Table 3: Repeatability data for dosulepin hydrochloride and methylcobalamin

\begin{tabular}{|c|c|c|c|}
\hline $\begin{array}{l}\text { Concentration of dosulepin } \\
\text { hydrochloride }\end{array}$ & $\begin{array}{l}\text { Peak area of dosulepin } \\
\text { hydrochloride }(n=6)\end{array}$ & $\begin{array}{l}\text { Concentration of } \\
\text { methylcobalamin }\end{array}$ & $\begin{array}{l}\text { Peak area of methylcobalamin } \\
(n=6)\end{array}$ \\
\hline \multirow{6}{*}{$330 \mu \mathrm{g} / \mathrm{ml}$} & 2883398 & $10 \mu \mathrm{g} / \mathrm{ml}$ & 248458 \\
\hline & 2844178 & & 245485 \\
\hline & 2861434 & & 244339 \\
\hline & 2888642 & & 243111 \\
\hline & 2900001 & & 247727 \\
\hline & 2833170 & & 248069 \\
\hline Mean & 2868471 & Mean & 246198 \\
\hline SD & 26493.98 & SD & 2210.877 \\
\hline$\%$ RSD & 0.92 & $\%$ RSD & 0.89 \\
\hline
\end{tabular}

\# n: Number of injections=6, \# SD: Standard deviation, \# \%RSD: Relative standard deviation

Table 4: Intraday and interday precision data for dosulepin hydrochloride and methylcobalamin

\begin{tabular}{|c|c|c|c|c|c|}
\hline \multirow[t]{2}{*}{ Drug } & \multirow{2}{*}{$\begin{array}{l}\text { Concentration } \\
(\mu \mathrm{g} / \mathrm{ml})\end{array}$} & \multicolumn{2}{|l|}{ Intra-day precision } & \multicolumn{2}{|c|}{ Intra-day precision } \\
\hline & & mean $\pm S D(n=3)$ & \% RSD & mean \pm SD $(n=3)$ & $\%$ RSD \\
\hline \multirow[t]{3}{*}{ Dosulepin hydrochloride } & 165 & $1475903 \pm 3817$ & 0.25 & $1499656 \pm 20976$ & 1.39 \\
\hline & 330 & $3075762 \pm 14929$ & 0.48 & $3125024 \pm 42235$ & 1.35 \\
\hline & 495 & $4714408 \pm 19769$ & 0.41 & $4731060 \pm 57485$ & 1.21 \\
\hline \multirow[t]{3}{*}{ Methylcobalamin } & 5 & $77230 \pm 645$ & 0.84 & $77273 \pm 1183$ & 1.53 \\
\hline & 10 & $157826 \pm 978$ & 0.62 & $156792 \pm 2612$ & 1.66 \\
\hline & 15 & $253929 \pm 1337$ & 0.52 & $254524 \pm 4647$ & 1.82 \\
\hline
\end{tabular}

\# n: Number of injections= 3, \# SD: Standard deviation, \# \%RSD: Relative standard deviation

\section{Accuracy}

The accuracy of the method was determined by recovery studies. The percent mean recovery of both the drugs at three different levels $(50 \%, 100 \%$ and $150 \%)$ was determined. The recovery studies were performed in triplicates for each level. The percentage recovery and mean percentage recovery calculated for the drug is shown in table 5 . The observed data were within the required range [20-21], which indicates good recovery values, affirming the accuracy of the method developed.

Table 5: Results of accuracy

\begin{tabular}{|c|c|c|c|c|}
\hline Drug & Level (\%) (n=3) & Amount taken $(\mu \mathrm{g} / \mathrm{ml})$ & Amount recovered (mean \pm SD) & \% Recovery \\
\hline Dosulepin & 50 & 165 & $164.64 \pm 1.196$ & 99.78 \\
\hline \multirow[t]{2}{*}{ hydrochloride } & 100 & 330 & $327.56 \pm 1.659$ & 99.26 \\
\hline & 150 & 495 & $495.03 \pm 3.673$ & 99.98 \\
\hline \multirow[t]{3}{*}{ Methylcobalamin } & 50 & 5 & $4.995 \pm 0.056$ & 99.96 \\
\hline & 100 & 10 & $9.92 \pm 0.027$ & 99.21 \\
\hline & 150 & 15 & $15.081 \pm 0.149$ & 100.56 \\
\hline
\end{tabular}

\#n: Number of injections= 3, \#SD: Standard deviation

\section{Robustness}

To determine the robustness of the developed method, experimental conditions were deliberately altered, and the system suitability parameter retention time and peak area were evaluated. The solutions prepared as per the test method described earlier and injected at different variable conditions like flow rate $(0.8,1,1.2$ $\mathrm{ml} / \mathrm{min}$.), mobile phase ratio of acetonitrile and phosphate buffer $(59: 41,60: 40,61: 39)$ and $\mathrm{pH}(2.8,3,3.2)$. The assessments of system suitability parameter like retention time and peak area were compared with that of method precision. The method was found to be precise as the \% RSD values calculated were within the limits for robustness [20-21] indicating method was robust. Robustness data are given in table 6 .

\section{Limit of detection (LOD) and Limit of quantitation (LOQ)}

LOD and LOQ were determined using the formulas, $\mathrm{LOD}=3.3 \times \mathrm{SD} / \mathrm{S}$ and $\mathrm{LOQ}=10 \times \mathrm{SD} / \mathrm{S}$, where, 'SD' is the standard deviation of the response and ' $\mathrm{S}$ ' is the slope of the calibration curve. The LOD and LOQ values were found to be $0.75 \mu \mathrm{g} / \mathrm{ml}$ and $2.28 / \mu \mathrm{g} / \mathrm{ml}$ for dosulepin hydrochloride and $0.040 \mu \mathrm{g} / \mathrm{ml}$ and $0.121 \mu \mathrm{g} / \mathrm{ml}$ for methylcobalamin. 
Shah et al.

Int J App Pharm, Vol 9, Issue 4, 2017, 69-75

Table 6: Robustness study for dosulepin hydrochloride and methylcobalamin

\begin{tabular}{|c|c|c|c|c|c|}
\hline \multirow[t]{2}{*}{ Parameter } & \multirow[t]{2}{*}{ Method condition } & \multicolumn{2}{|c|}{ Dosulepin hydrochloride } & \multicolumn{2}{|c|}{ Methylcobalamin } \\
\hline & & Retention time & Peak area & Retention time & Peak area \\
\hline \multirow[t]{4}{*}{ Flow rate $(\mathrm{ml} / \mathrm{min})$} & 0.8 & 8.002 & 3030254 & 1.993 & 154856 \\
\hline & 1.0 & 7.991 & 3088441 & 1.972 & 157257 \\
\hline & 1.2 & 7.921 & 3091163 & 1.956 & 159635 \\
\hline & $\%$ RSD & 0.55 & 1.12 & 0.9 & 1.51 \\
\hline \multirow[t]{4}{*}{ Mobile phase ratio-acetonitrile: phosphate buffer } & $59: 41$ & 7.958 & 3046672 & 1.966 & 153563 \\
\hline & $60: 40$ & 7.991 & 3088441 & 1.972 & 157257 \\
\hline & $61: 39$ & 8.006 & 3093753 & 1.994 & 155209 \\
\hline & $\%$ RSD & 0.31 & 0.83 & 0.74 & 1.19 \\
\hline \multirow[t]{4}{*}{$\mathrm{pH}$} & 2.8 & 7.969 & 3092528 & 1.963 & 156843 \\
\hline & 3.0 & 7.991 & 3088441 & 1.972 & 157257 \\
\hline & 3.2 & 7.948 & 3074510 & 1.983 & 154621 \\
\hline & $\%$ RSD & 0.26 & 0.30 & 0.51 & 0.91 \\
\hline
\end{tabular}

\#\% RSD: Relative standard deviation

\section{Forced degradation studies}

Forced degradation studies were performed to demonstrate the stability of the sample in different stressed conditions. The conditions used were acid and base hydrolysis, dry heat, oxidation and sunlight photolysis. The acid hydrolysis showed little degradation of dosulepin hydrochloride and methylcobalamin with degraded products peaks at retention time 7.223 and 2.903. For alkali degradation, degraded product peak was observed at retention time 6.957 and 3.543. Degradation studies under oxidative conditions gave degraded product peaks at retention time 6.943 and 3.867. For the thermal degradation, peaks were observed at retention time 7.497 and 2.790 for degraded products. In photohydrolysis, degraded product peaks were observed at retention time 9.447 and 2.737 .

The data for forced degradation are tabulated in table 7. There was no interference of any peak at the retention time of analytes from the blank. RP-HPLC chromatograms for degradation of dosulepin hydrochloride and methylcobalamin can be seen in fig. 7 .

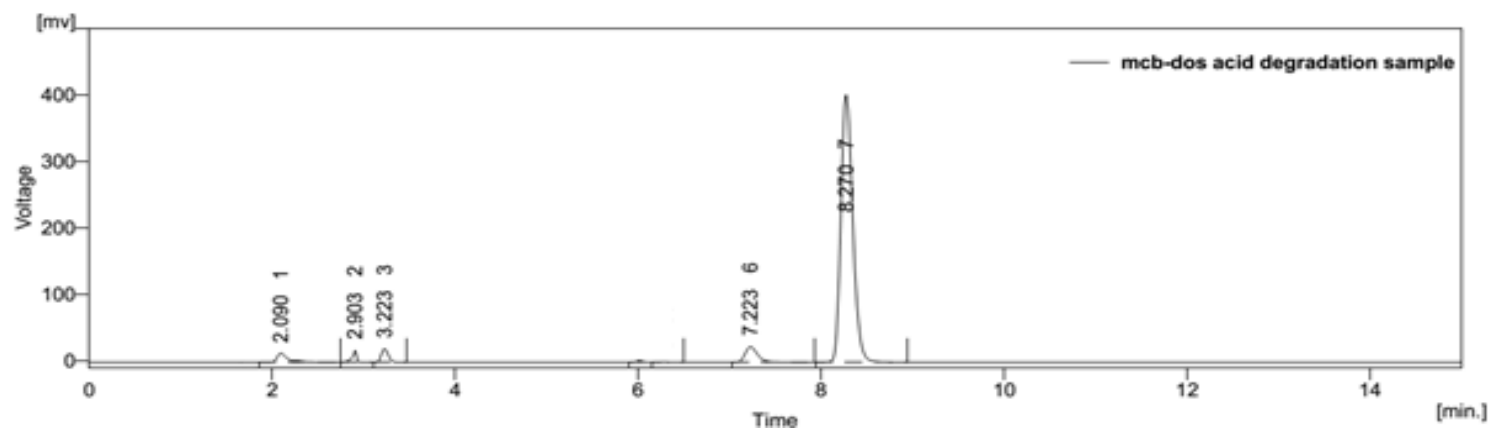

(A)

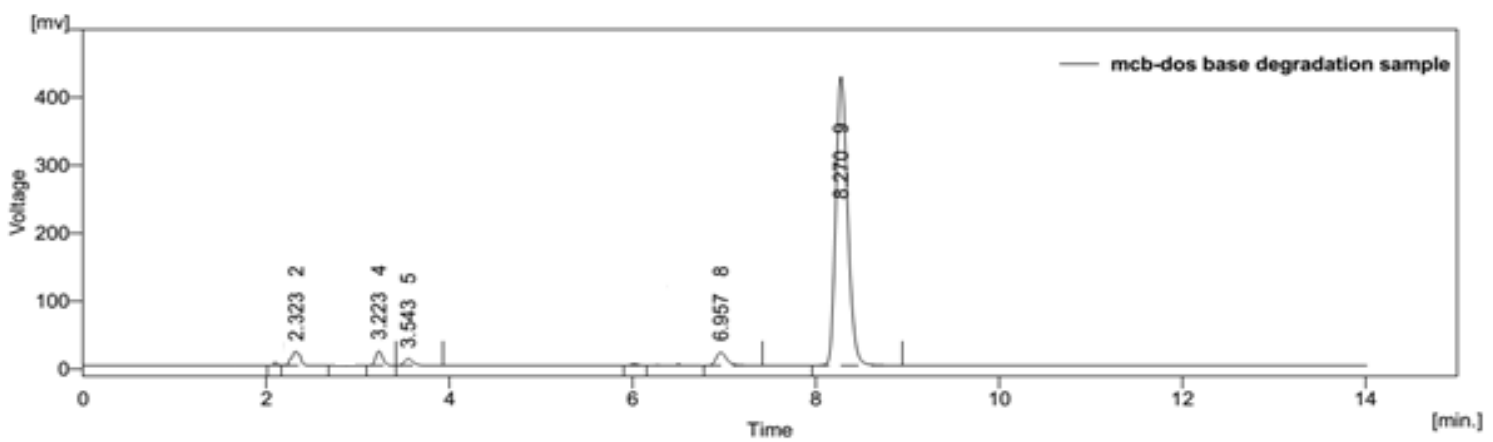

(B)

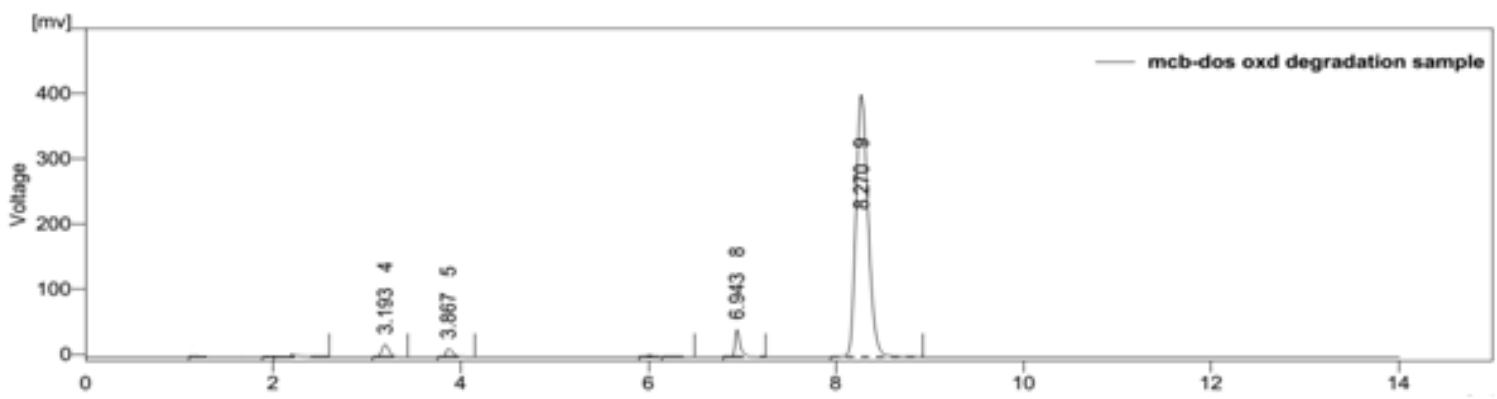

(C) 


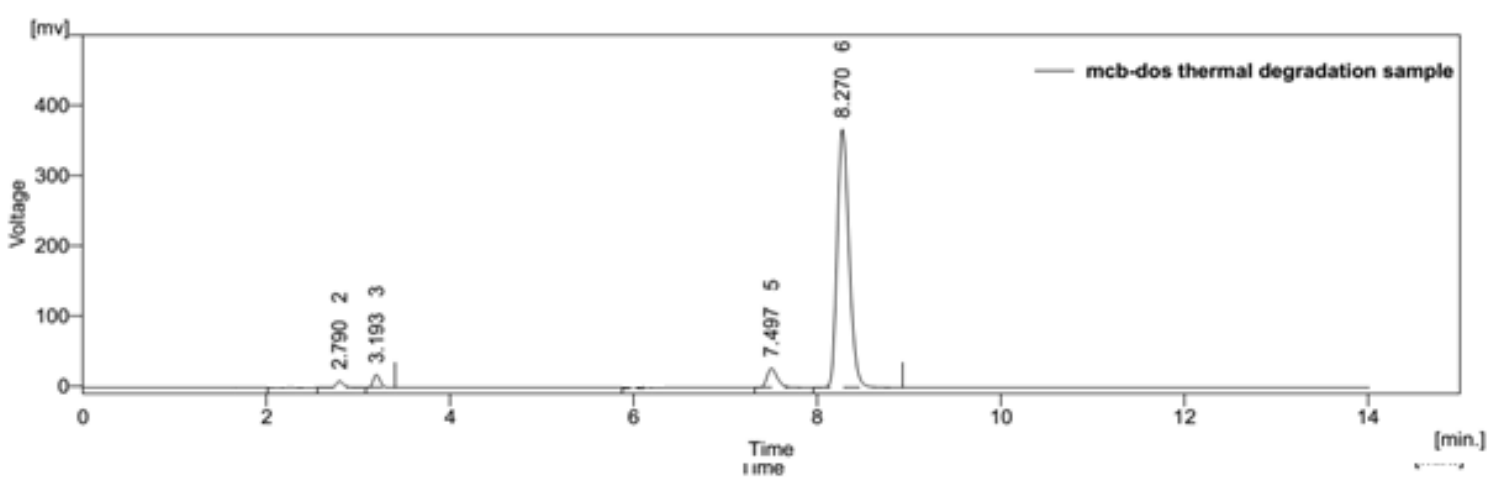

(D)

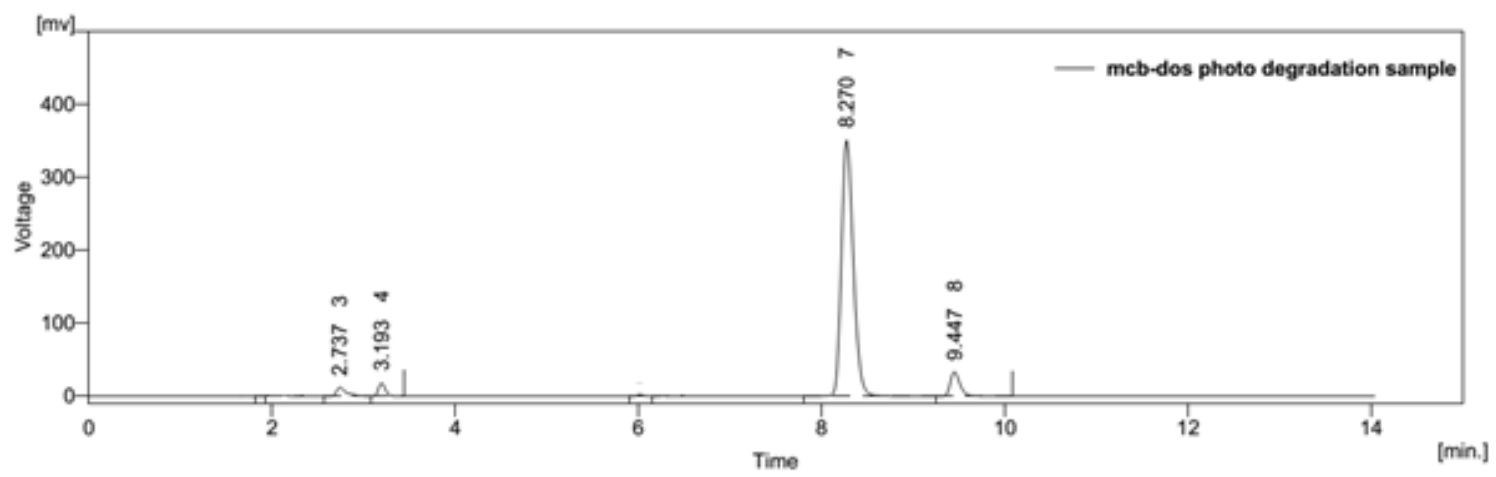

(E)

Fig. 7: Representative chromatograms of acid (A), base (B), oxidative (C), thermal (D), and photolytic (E) degradation of dosulepin hydrochloride and methylcobalamin

Table 7: Forced degradation data

\begin{tabular}{llll}
\hline S. No. & Condition applied & \% degradation & Methylcobalamin \\
\cline { 3 - 4 } & & Dosulepin hydrochloride & $22.71 \%$ \\
\hline 1 & $0.1 \mathrm{M} \mathrm{HCl}$ & $26.39 \%$ & $22.51 \%$ \\
2 & $0.1 \mathrm{M} \mathrm{NaOH}$ & $22.59 \%$ & $34.30 \%$ \\
3 & $3 \% \mathrm{H} 202$ & $28.56 \%$ & $29.72 \%$ \\
4 & Heat treatment & $32.48 \%$ & $38.20 \%$ \\
5 & Photolysis & $36.40 \%$ & $2 \%$ \\
\hline
\end{tabular}

In previous report [17] dosulepin hydrochloride and methylcobalamin were assayed using Inertsil-ODS $(250 \times 4.6 \mathrm{~mm}, 5 \mu \mathrm{m})$ column with mobile phase containing $0.02 \%$ orthophosphoric acid and methanol (400:600 v/v), whereas this study uses a novel column, Kromasil $\mathrm{C}_{18}$ $(250 \times 4.6 \mathrm{~mm}, 5 \mu \mathrm{m})$ column with novel mobile phase consisting of acetonitrile: phosphate buffer pH 3.0 (60:40) wherein retention time of 1.972 for methylcobalamin and 7.991 for dosulepin hydrochloride with better resolution is found. Moreover, various reports of assaying these compounds alone or in other combinations exist but the method developed in this report is first of its kind.

\section{CONCLUSION}

The proposed study, a new stability-indicating RP-HPLC method has been developed for estimation of dosulepin hydrochloride and methylcobalamin in bulk and pharmaceutical dosage form. The developed method was validated and it was found to be simple, sensitive, precise, and robust and it can be used for the routine analysis of dosulepin hydrochloride and methylcobalamin in both bulk and pharmaceutical dosage forms. The forced degradation studies were carried out in accordance with ICH guidelines and the results revealed suitability of the method to study the stability of dosulepin hydrochloride and methylcobalamin under various degradation conditions like acid, base, oxidative, thermal, and photolytic degradations. Finally, it was concluded that the method is simple, sensitive and has the ability to separate the drug from degradation products and excipients found in the dosage form.

\section{ACKNOWLEDGEMENT}

The authors wish to thank Elite Pharma, Ahmedabad and Aum Laboratory, Ahmedabad for providing gift samples.

\section{CONFLICT OF INTERESTS}

Authors have no conflict of interest

\section{REFERENCES}

1. Shibanoki S, Imamura Y, Arakawa Y, Ishikawa K. Determination of dosulepin and its metabolite: application of highperformance liquid chromatography with electrochemical detection. J Chrom B Biomed Sci Appl 1987;415:365-7.

2. http://www.chemspider.com/Chemicalstructure.4445579.html. [Last assessed on 09 Jul 2015].

3. Mostafa Y, Mamdouh G, Mostafa K, Shadeed G. Effect of additives on the intranasal preparation of cyanocobalamin. Int J Pharm Pharm Sci 2015;7:210-7.

4. Saba M, Tejaswi B, Chitra K, Gnanamani A. Metal complexes in the management of diabetes mellitus: a new therapeutic strategy. Int J Pharm Pharm Sci 2014;6:40-4.

5. Mejo CK, Junaid RPV, Rajeswari R, Ahana B, Elizabeth PP Sivakumar T. Adverse effects and side effects on vitamin therapy: a review. Asian J Pharm Clin Res 2017;10:19-26.

6. http://en.wikipedia.org/wiki/Methylcobalamin. [Last assessed on 09 Jul 2015] 
7. Walash MI, Belal F, El-Enany N, Elmansi H. Spectrophotometric and spectrofluorimetric methods for the determination of dothiepin hydrochloride in its pure and dosage forms using eosin. Int J Biomed Sci 2010;6:327-34.

8. Abdulrahman SAM, Basavaiah K, Cijo MX, Vinay KB. Validation of UV spectrophotometric methods for the determination of dothiepin hydrochloride in pharmaceutical dosage form and stress degradation studies. J Appl Spectrosc 2012;79:780-7.

9. Abdellatef HE, El-Henawee MM, El-Sayed HM, Ayad MM. Spectrophotometric and spectrofluorimetric methods for analysis of tramadol, acebutolol and dothiepin in pharmaceutical preparations. Spectrochim Acta Part A 2006;65:1087-92.

10. Kumar VD, Mahesh MN, Gurupadayya BM, Ravi V. Simultaneous estimation of citalopram hydrobromide and dothiepin hydrochloride in human plasma by HPLC method. J Pharm Res 2011;4:50-2.

11. Narmada P, Vijaya LG, Nalini G. RP-HPLC method developmend and valdation for the determination of methylcobalamin and pregabalin in the combined capsule dosage form. Int J Res Pharm Sci 2013;4:25-9.

12. Varsha RG, Baheti KG, Dehghan MH. UV-Vis spectrophotometric method for estimation of gabapentin and methylcobalamin in bulk and tablet. Int J Chem Tech Res 2010;2:695-9.

13. Sharma MC, Sharma S, Sharma AD. Simultaneous estimation and validation of gabapentin and methylcobalamin in tablet dosage form: hydrotropic approach. Drug Invention Today 2011;3:95.

14. Sheladia S, Patel B. Implementation of QBD approach to develop and validate an analytical method for simultaneous estimation of duloxetine hydrochloride and methylcobalamin in pharmaceutical dosage form by HPTLC method. Int J Pharm Pharm Sci 2016;8:105-13.

15. Usharani G, Chandrashekar B, Devanna N. Simultaneous estimation of dosulepin and methylcobalamin in bulk and pharmaceutical formulation by reverse phase highperformance liquid chromatography (RP-HPLC). IOSR J Pharm Biol Sci 2014;9:55-9.

16. Desai DB, Shah DA, Mehta FA, Chhalotiya UK, Bhatt KK. Liquid chromatographic estimation of dosulepin $\mathrm{HCl}$ and methylcobalamin in a pharmaceutical formulation. Res Rev: J Pharm Nanotechnol 2014;2:29-35.

17. Reddy LSK, Reddy DSLNP, Reddy GS. Validated stability indicating a liquid chromatographic method for simultaneous estimation of dosulepin and methylcobalamin in combined pharmaceutical dosage form. Orient J Chem 2014;3:1243-51.

18. ICH, Q2A Text on validation of analytical procedures, International Conference on Harmonization, Geneva; 1994. p. 1-5.

19. ICH, Stability testing of new drug substances and products (Q1AR2), International Conference on Harmonization, IFPMA, Geneva; 2003.

20. FDA, Guidance R. Validation of chromatographic methods. center for drug evaluation and research (CDER), Food and Drug Administration; 1994. p. 2.

21. FDA, ORA validation and verification guidance for human drug analytical methods. Food and Drug Administration; 2003. p. 1.

\section{How to cite this article}

- $\quad$ Radhika Shah, Ragin Shah. Stability indicating RP-HPLC method for simultaneous estimation of dosulepin hydrochloride and methylcobalamin in tablet dosage form. Int J Appl Pharm 2017;9(4):69-75. 